\title{
Translation Competitions in Educational Contexts: A Positive Psychology Perspective
}

\author{
Piotr Szymczak
}

\begin{abstract}
A central experience in human interactions, competition has a long history in education. It has been valued for bringing out the best in learners and criticized for the harms it may inflict on unsuccessful and successful participants alike. This paper looks at data from two formal translation competitions held at the Institute of English Studies (University of Warsaw) to report on the reactions and motivations of the participants. The data is examined from the perspective of the PERMA model of wellbeing as proposed by Seligman (2011). Insights from positive psychology inform recommendations on how we can design better competitions in educational contexts by ensuring transparent assessment procedures, increased success rates, and proper guidance to participants through tips and feedback.
\end{abstract}

Keywords Positive psychology - Education - Competitions - Competitions in education - Translator training

\section{Introduction}

Competition, whether arising spontaneously or introduced by design, has a long history and can be seen as an inseparable part of educational systems. It was highly prized in the classical cultures of Europe, rooted as they were in the agonicity of oral cultures: just as successful athletic contestants in ancient Greece were given hero status, early Greek rhetorical and philosophical education was similarly designed as a battle of wits, encouraging competitive instincts. Romans similarly valued competition (aemulatio) as a tool for promoting positive examples, increased effort and improved performance. Alit aemulatio ingenia: et nunc invidia,

\footnotetext{
P. Szymczak ( $\bowtie)$

Institute of English Studies, University of Warsaw, ul. Hoża 69, 00-681 Warsaw, Poland e-mail: piotrszymczak@uw.edu.pl 
nunc admiratio imitationem ascendit ("Emulation [i.e., competing with others] quickens our Endeavours: sometimes we are spurred on by Envy, sometimes by a generous opinion of the Excellence of a Work", a Roman historian noted approvingly) (Paterculus, 1721, p. 33).

Competition made its way into modern educational systems as an essential aspect of learning. In the nineteenth and early twentieth century schools pupils were explicitly ranked within their form (class) according to ability and academic performance, a practice which has left traces in the Polish language, where a straight-A student is still called a prymus, derived from the Latin primus or "the first". The same principle survives in the curved grading systems used in many universities today, where grades do not reflect absolute values but rather an individual student's performance relative to the scores of the remaining group members (converted to grades or expressed in percentile terms). Curved grading can be seen as a method for preventing grade inflation (when used as a tool of internal assessment, as is the case in many universities and instructors) or a policy tool used for diagnosing underperforming institutions, but at the same time it makes competition an intrinsic part of educational assessment.

Given the near-universal incidence of competition in educational contexts it is important to examine the effects of competition on students' wellbeing with a view to improving the format. This article looks at one aspect of this problem, namely formal competitions in a tertiary educational context. The competitions in question were organized at the Institute of English Studies, University of Warsaw, and were followed up with a questionnaire inviting the participants to reflect on various aspect of the experience. For its conceptual framework the article relies on the PERMA model of wellbeing proposed by Martin P. Seligman as a tool for operationalizing the various aspects of individual flourishing. The PERMA model, and positive psychology more generally, has found application in educational context from its very beginning (see Chap. 5 in Seligman, 2011). It has recently come to be applied in a systematic fashion in the field of second language acquisition (see Mercer \& MacIntyre, 2014), a survey article summarizing the key tenets of positive psychology, and situating its contributions within the broader historical context of SLA studies).

\section{Dataset and Study Methodology}

The two competitions in this study were formally organized and held at the Institute of English Studies (University of Warsaw). The first competition, called "Book to World", was a literary translation competition held in December 2013 to recruit a group of student translators who would be invited to join a genuine book translation project (a translation of the complete short stories by Oscar Wilde into Polish, due out in e-book and paperback formats in 2016). This competition (abbreviated here to the "LTC" or the Literary Translation Competition) involved translating a short sample of Wilde's work (500 words). It was open to all students at the Institute of 
English Studies and to external entrants (by arrangement), and advertised with wall posters and online on the Institute website and Facebook fan page.

The second competition, "Tłumacze na start" was the preliminary stage in a larger business translation competition organized in October 2014 by Skrivanek Sp. z o.o., the Warsaw branch of an international translation agency. The Institute of English Studies in Warsaw was a partner institution responsible for organizing the first stage of the competition for our students locally, and the competition was only open to students at the Institute of English Studies. In this competition, the entry involved translating a short Business English sample provided by Skrivanek for translation into Polish.

For each competition, an assessment procedure was designed and rigorously followed to ensure unbiased selection criteria to eliminate possible assessment bias. The entries were coded to ensure anonymity, and they were judged on two metrics, translation accuracy and stylistic quality. A total of 37 students entered their translations for consideration in the Literary Translation Competition (LTC), 11 of whom were selected for the translation project (success rate: $29.7 \%$ ). In the Business Translation Competition (BTC), 17 students entered and three were selected to go on to the final nationwide stage (success rate: $17.6 \%$ ). Two of the three ultimately became winners (placed first and third in the nationwide stage).

Participants in those two competitions were invited to take part in an anonymous survey using the Google Forms platform to offer feedback on their impressions of the competition procedures. The survey consisted of 12 questions rating different aspects of the experience on a standard Likert-style scale (1-5). An open question was provided at the end for unscripted recommendations on improvements. The invitations were sent as separate messages and personalized to achieve a higher response rate, an approach which yielded a response rate of $82.5 \%$ (47 out of 57 participants completed the survey), considerably exceeding the typical rates achieved in either standard research questionnaires (cf. Cook, Heath, \& Thompson, 2000 , p. 826) or "course experience" feedback forms used in educational environments (cf. Nulty, 2008, p. 306). The response rate for the BTC was $94.1 \%$ (16 out of 17), and the response rate for the LTC was $78.3 \%$ (29 out of 37).

Given the size of the sample, the findings cannot be meaningfully analyzed in terms of variables or reliably extrapolated to larger populations, however the high response rate means that the study offers a representative snapshot of the participants' opinions, and provides a good starting point for further research.

The responses to the questionnaire produced a picture that was interesting and often surprising. In some cases, the respondents reacted to the competition experience in ways that were unsettlingly different from how mature translators would approach the same situation. Those differences are transparently a matter of young age and inexperience (the study subjects were all students enrolled in the Institute of English Studies BA and MA programs, so they were predominantly in the 20-25 age bracket), however they suggest that certain modifications and safeguards are required to make sure that competitions are a positive and productive experience. 


\section{Competitions in Education: The Harms}

Despite the all-pervasive presence of competition in educational context since the beginnings of formal education (or rather precisely because of it), the classical way of looking at competition as a way of bringing the best out of people came to be forcefully challenged in the late twentieth century. Most notably, the challenge came from the American author Alfie Kohn, who emerged in the 1980s as a vocal opponent of any form of competition in education.

Because failure as well as success is implicit in competitions, Kohn regarded competition as intrinsically negative. He argued that a competitive mindset shoehorns people into perceiving others as obstacles to success rather than partners and allies, and cites research showing that competitive arrangements in education, far from being conducive to improved performance, either make no difference at all or are positively harmful. He concluded that "[t]he best amount of competition for our children is none at all" (Kohn, 1987).

Alfie Kohn's radical critique of the current American educational system attracted interest as well as criticism. His critics conceded the validity of many of his points, and acknowledged his role in spurring a rethinking of the fundamentals of teaching in a system stifled by standardization, but they also criticized Kohn's extreme positions ("Kohn has made a virtual industry out of finding interesting and provocative insights in the psychological literature and following them off the edge of a cliff" (Willingham, 2009) or pointed out the blind spots in his evidence and arguments (Petrilli, 2012).

Such criticisms notwithstanding, Kohn's critique of the educational system remains valid, especially in the broader sense that a focus on competition, though it might prompt individuals to work harder, can still be counterproductive by undercutting the benefits of collaboration and ruining schools as natural critical learning environments (a term proposed by Ken Bain in a different context in his excellent study of high-performing college teachers (Bain, 2004), i.e., environments where students focus on personal growth, and success is defined in terms of meaningful, productive and socially useful projects. Bain notes that although some people react well to competition and are motivated to work harder by mentally framing their efforts as a "quest for gold", such people are usually unlikely to genuinely care for the material in question. Instead, they become "strategic learners", who learn material for the test and then forget it to make room for a new challenge (Bain, 2004, loc. 439-41).

We might add another criticism to this list, namely the inherently random nature of success and failure in formal competitions. Like Graham Greene, who famously entered a New Statesman competition requesting parodies of his work in 1965 and only won a honorable mention for his own work submitted under a pseudonym (Hill \& Wise, 2012, p. 166), students taking part in competitions face much uncertainty without necessarily realizing it. In the experience of this author, who 
personally organized and judged the two competitions, competitions pose a unique challenge to fair and objective appraisal as mood or personal opinion can influence the appraisal at an unconscious level (Kahneman, 2011). Accordingly, steps were taken to remove possible bias from tiredness and ego depletion (see Chap. 3 of Kahneman, 2011, see also Danziger, Levav, \& Avnaim-Pesso, 2011), as well as the consequences of the halo effect (see Chap. 7 of Kahneman, 2011).

In this instance, all competition entries were carefully anonymized to remove grading bias caused by the halo effect, and a standardized appraisal procedure was used based on the number and severity of translation errors. Nonetheless, given the similar quality of performance from many of the participants, the difference between winning and losing was often a matter of a single minor and easily remediable mistake too many. Combined with the fact that success or failure in a well-attended competition is influenced by factors completely beyond the participants' control (such as tiredness, honest mistakes or idiosyncratic stylistic preferences on the part of the judges), the outcome of a competition, while not exactly random, can be disconcertingly haphazard.

This is particularly unfortunate given that nearly all of the participants seemed to treat competitions as a test of skill. The among the possible motives for entering a competition as explored in the post-competition questionnaires (with questions asking the participants to rate their motivations in terms of new experience, networking opportunities, test of skill, meaningful project or professional advancement), the idea to test one's skills and get a "reality check" was by far the most important motivation for the participants. $93 \%$ of the respondents reported that the reason they took part was to put their skills to a test and see what they are worth as translators. Given that virtually all of the participants were either still in training or were, at best, novices with limited professional experience, this is a dangerous misconception that needs to be addressed in any well-designed competition format (Table 1).

Table 1 Participant motivation

\begin{tabular}{l|l|l|l|l|l}
\hline $\begin{array}{l}\text { Motivation } \\
\text { factor }\end{array}$ & $\begin{array}{l}\text { (1) } \\
\text { Unimportant }\end{array}$ & $\begin{array}{l}\text { (2) } \\
\text { Somewhat } \\
\text { important }\end{array}$ & $\begin{array}{l}\text { (3) Neither } \\
\text { unimportant nor very } \\
\text { important }\end{array}$ & $\begin{array}{l}\text { (4) } \\
\text { Important }\end{array}$ & $\begin{array}{l}\text { (5) Very } \\
\text { important }\end{array}$ \\
\hline $\begin{array}{l}\ldots \text { put your } \\
\text { skills to a test }\end{array}$ & 1 & 0 & 2 & $\mathbf{1 3}$ & $\mathbf{2 6}$ \\
\hline $\begin{array}{l}\ldots \text { gain a new } \\
\text { experience }\end{array}$ & 1 & 2 & 3 & $\mathbf{2 0}$ & $\mathbf{1 5}$ \\
\hline $\begin{array}{l}\ldots \text { establish } \\
\text { new contacts }\end{array}$ & 11 & 12 & 10 & 6 & 4 \\
\hline $\begin{array}{l}\ldots \text { do } \\
\text { something } \\
\text { meaningful }\end{array}$ & 3 & 2 & 5 & 17 & 16 \\
\hline $\begin{array}{l}\text { C. boost your } \\
\text { CV }\end{array}$ & 6 & 1 & 6 & 13 & 17 \\
\hline
\end{tabular}

"In terms of your motivation to take part, how important was it for you to..." 


\section{Competitions: The Positives}

On the other hand, Kohn's horror of exposing children to failure is arguably itself a culturally induced blind spot which may short-change learners by depriving them of the positives of success and, equally importantly, failure. Although our educational systems tend to treat failure as a clear negative, attitudes towards failure in education deserve to be reprogrammed so we can treat failure for what it is, an important piece of feedback on one's educational efforts. A recent highly acclaimed and bestselling book on effective thinking (Burger \& Starbird, 2012) argues persuasively that developing a positive and open-minded attitude to failure is a necessary factor in building a creative intellectual mindset, and insists that failure is an inseparable element of the creative process. Similarly, a recent review article looking at current views on competition in education (Pandel, 2015) points to more evidence of this mindset in recent educational psychology literature, where failure is treated as an important experience teaching learners to "identify the problems, remedy the deficiencies, reset their goals, and grow from their experiences" (Rimm, 1995, cited in Pandel, 2015). Such research findings help provide a more balanced view where competition is seen not so much as a natural condition as a life skill, to be deliberately taught and mastered (Shields \& Funk, 2011).

In the context of tertiary education, success in a competition can also be a valuable asset on the job market, boosting the winner's social capital and marketability. As headlines like "Why You Should Hire for Potential, Not Experience" (Wisenberg Brin, 2015) make clear, some employers will always be inclined to bet on an exciting candidate rather than choose a safe pair of hands with a proven track record. By adding competition success to their resume, candidates can stand out from the crowd.

\section{PERMA and Competitions}

Given the prevalence, complex nature and range of potentially harmful or positive effects, this article will examine formal competitions in terms of the five components of wellbeing (PERMA).

The concept of PERMA was formulated by Martin P. Seligman in his book Flourish (2011). The name is an acronym, which stands for positive emotion, engagement, relationships, meaning and accomplishment. In Seligman's approach (Seligman, 2011, pp. 13-18) the five elements of wellbeing form a construct where each element is independent of the others, and not required in equal measure in the life of every individual. With this approach, Seligman seeks to refine his own earlier model of "authentic happiness", where happiness was perceived as a holistic appraisal predominantly (and, Seligman concedes, unduly) determined by mood and general life satisfaction. Instead, the PERMA model seeks to avoid what Seligman recognized as a simplistic and one-dimensional approach to human flourishing, and replaces it with a more rounded and customizable model which gives due attention to factors not directly related to mood. 
Like positive psychology itself, which from the very beginning found applications in the educational system, each of those component elements of wellbeing has been recognized as a factor in ensuring more effective learning environments for better instruction. As the following findings demonstrate, the components of the PERMA model are also highly relevant to the experience of participating in a competition, and can therefore provide useful insights we can use to design more effective competitions by amplifying the strengths, and mitigating the harms involved.

\subsection{Positive Experience}

One obvious form of positive experience in a competition is winning one. The psychological impact of success or failure depends on how important the competition was to the person in question. When asked, "How much did the competition matter to you (in any way: emotional, professional, educational, etc.)?", the participants reported, on average, high motivation levels, with more than $76 \%$ of the participants reporting of the competition was important (response: 4.0) or very important (response: 5.0) to them (average value: 3.93). The picture becomes even clearer when we split the answers into successful and unsuccessful candidates. More than $85 \%$ of the successful candidates reported that the competition was "important" (8 people out of 14) or "very important" to them (4 people out of 14), with a high average answer value of 4.14 . The competition apparently mattered less to the unsuccessful candidates, but 21 people out of 29 still found it to be important or very important to them, with an average value of 3.83 .

In both competitions under discussion here, a great majority of the winners reported finding success highly enjoyable ("How positive/negative was the experience of success/failure in your case?", with an average response of 4.5, and $86 \%$ of the respondents ranking success as "enjoyable" or "highly enjoyable". However, because competitions are typically zero-sum games (where one person's loss is another person's gain), they have an inherent potential for causing a negative experience for the unsuccessful competitors. Most unsuccessful candidates tried to keep stiff the upper lip, but $38 \%$ per cent admitted to feeling that their failure was "disappointing" or "very disappointing", with a further $34 \%$ reporting ambivalent feelings ("neither disappointed nor not disappointed"). Only one person in 29 reported not being in the slightest upset by their failure.

Given the low success rates sewn into most competition formats, a well-designed competition should move beyond the zero-sum mind frame, and highlight the positives and potential benefits of participation to the unsuccessful candidates. Where possible, the competition could involve non-competitive gains in the form freebies, snacks and positive verbal messaging. Also, competitions with a reasonable success ratio are preferable to highly selective competitions, and effort should be made to provide positive or productive feedback to the unsuccessful candidates. 


\subsection{Engagement}

In Martin P. Seligman's PERMA model, "engagement" is practically synonymous with Mihaly Csikszentmihályi's concept of flow, a desirable and energizing experience of complete immersion in a task (Seligman, 2011, p. 11). The fact that Seligman's model of wellbeing places great importance on flow/engagement, on a par with more conventional and intuitive aspects of human flourishing, is a reflection of the growing interest in, and appreciation of, Csikszentmihályi's concept of optimal experience since his early publications on the subject (Csikszentmihályi, 1988, 1990). Sine the 1990s, the concept of flow generated a number of popular and scholarly publications by Csikszentmihályi and others, focusing on various areas of human experience (creativity, sport, business ethic and professional performance, everyday life, etc.), and remains important in current research (Csikszentmihályi, 2003).

It might seem optimistic to look for the experience of flow or "being in the zone" in a student competition: flow is typically achieved when challenging activities are flawlessly and uninterruptedly performed by individuals performing at the top of the abilities, not a situation usually associated with novice translators. However, as Csikszentmihályi noted in his seminal book on the subject, flawless performance in this context is a matter of personal perception rather than an absolute point of reference. It is perfectly possible for less than completely masterful performers to experience flow provided that the goals are clear, the feedback is immediate and there is a balance between opportunity and capacity (i.e., the task is perceived as realistic and doable) (Csikszentmihályi, 1990, p. 42-56).

In the study, the question designed to test the occurrence of flow was "To what extent would you agree with the following statement 'When working on my entry, for long stretches of time I became so intensely involved that I lost track of time and everything around me'?" A majority of the participants (24 out of 43 , or $56 \%$ ) either agreed (4), or very much agreed (5) that they had experienced intense involvement, meaning that they had lost track of time and everything around them when working on their competition entries, and only 9 people out of $43(21 \%)$ reported having had no experience of flow (by indicating answers 1 or 2). This suggests that competitions have considerable potential for generating flow in participants. In as much as possible, a well-designed competition should therefore aid the flow experience by providing clear information on competition procedure, requirements, expectations and appraisal criteria.

\subsection{Positive Relationships}

Positive relationships are recognized as a crucial dimension of the modern workplace, as evidenced in the growing interest in human resources management and emotional/social intelligence in the workplace, and it is probably not coincidental that positive relationships (the "P" in PERMA) are the first letter in that acronym. 
On the face of it, positive relationships are inherently a weak spot of translation work. The social isolation and under-stimulation involved in working from home on long texts is the stuff of industry lore, fondly shared on social media. And translation competitions, where individuals are working alone, pitted against one another and feeling increased pressure of scrutiny, can be doubly isolating. This said, an experienced translator (or any experienced member of the workforce) would be quick to realize the pragmatic benefits of participating in a competition, to be gained from growing one's network of professional contacts.

In the case of student participants, probably as a result of inexperience, this networking aspect of positive relationships was given a fairly low priority. When asked the question, "In terms of your motivation to take part, how important was it for you to establish new contacts", the mean value of the responses was 2.53 . Only $23 \%$ of the respondents felt that making new contacts through the competition was "important" (4.0) or "very important" (5.0) to them.

However, a more productive approach to translation competitions is possible. Although formal success ("winning" a competition) is inherently uncertain and unlikely, any competition involves meeting new the organizers and fellow participants, which may be a positive experience in a personal sense and, more pragmatically, a useful addition to one's network of professional contacts. This is why an experienced translator would be more likely to enter a competition in a sort of calculated bet, treating success an attractive but distant incentive, and new business contacts as a pragmatic and certain gain.

Despite the isolated nature of the experience (or perhaps because of it), positive relationships turned out to have been important to participants in a different way, namely in terms of the social affirmation and emotional support provided by friends and loved ones. When asked whether they publicized their success ("Did you share the news of your success/failure with other people - in person, on social media, etc.?"), $86 \%$ of the "winners" reported having shared the good news with "many" (4) or "vary many" (5) friends and/or loved ones. Only $24 \%$ of the participants were as forthcoming in the unsuccessful group, however even in this group there weren't many people ( 5 out of 29 , or $17 \%$ ) who kept the bad news completely to themselves (1) - most people in the unsuccessful group chose to confide in a smaller, presumably more select group of confidants.

\subsection{Meaning}

The need for meaning in education is an insight of great antiquity. Personal relevance was recognized as being of central importance already in Socrates' remarks on education in The Republic. The recognition that learning should be pursued for personal relevance rather than for the sake of school or grades is already a commonplace in the Stoic letters of Seneca, who bemoans the excessive academicism which lures people into learning "not for life, but for the lecture-room" (scholae, non vitae discimus) (Seneca, 1925, Letter 106, line 12). The formative influence of 
learning is acknowledged in the educational projects of 15th- and 16th-century humanists, and made a particularly major impact in latter centuries thanks to the ideas of Comenius or Jan Ámos Komenský (1592-1670).

In Seligman's model, meaning is strongly related to the social dimension of life. In PERMA, meaning consists in doing work that serves a higher purpose of some kind (political, social, religious, ideological, personal, etc.) (cf. Seligman, 2011, pp. 12, 17-18). Again, this is an insight that predates positive psychology, and features prominently in modern approaches to pedagogy. For instance, the humanistic (person-centered) education pioneered by Abraham Maslow and Carl Rogers views teachers as facilitators who help individuals to achieve a meaningful educational experience. Similarly, social constructivism treats teachers as elements of "scaffolding" to help learners scale heights they cannot otherwise reach on their own, and engage in authentic work of personal and social relevance and utility.

The importance of meaningful work is recognized in formal education, including formal translator training, but socially productive work is not always easy to arrange in educational contexts, even in an inherently practical fields like translator training cf. (Nord, 2005; for a way to address this systemic shortcoming using digital platforms like Wikipedia see Szymczak, 2013).

In this study, there was an aspect of personal relevance and/or social utility to both competitions: winners of the literary translation competition qualified to translate and publish an actual book, and winners in the business translation competition had could hope for increased employment opportunities (an internship with the organizer's translation agency was one of the prizes, and first-stage winners stood to gain increased professional recognition).

Accordingly, meaning mattered to the participants. When asked, "In terms of your motivation to take part, how important was it for you to improve your CV", the average answer value was a high 3.79 . More than $70 \%$ of the participants reported that this consideration was important (13 out of $43,30 \%$ ) or very important (17 out of 43, $40 \%$ ) to them. An even more general and straightforward question, "In terms of your motivation to take part, how important was it for you to do something meaningful in life", garnered an even stronger positive response. $77 \%$ of the participants answered that this motivation was either important (4) or very important (5) to them, with a high average value of 3.95. This ties in with the fact that the participants generally found the competition important, personally (average value: 3.93 , with $77 \%$ participants finding the competition important or very important). This suggests that a well-organized competition should ideally involve work which is meaningful. Also, it is important to turn participation into a learning opportunity, giving more meaning to the experience.

\subsection{Achievement}

In Seligman's model, achievement/accomplishment is a crucial component of wellbeing since people often pursue and prize success for its own sake (Seligman, 
2011, p. 18-20). Seligman devotes considerable attention to accomplishment and its relationship with predictive factors such as intelligence, individual explanatory styles or GRIT (a ratio measuring individual levels of "sticktoitiveness" developed by Angela Lee Duckworth, which is a strong predictor of an individual's future success) (cf. Duckworth \& Quinn, 2009; Seligman, 2011, pp. 101-125,).

Achievement is an inherent aspect of competition, and the high average value of responses relating to publicizing success (4.14, with $86 \%$ of successful candidates being open or very open about their success) suggests a strong degree of social amplification. As mentioned above, $86 \%$ of the winners (12 people) felt that success was "enjoyable" (three people) or "very enjoyable" (nine people).

As self-reported by the participants, this sense of accomplishment can be highly motivating. When asked, "To what extent was your success encouraging in your plans to become a professional translator?", only two of the 14 successful participants indicated that the experience was "neither encouraging nor discouraging" (answer value: 3.0). The remaining twelve winners (86\%) felt that success was "encouraging" (answer value: 4.0) or "very encouraging" (answer value: 5.0). This effect is presumably heightened wealth the competition is perceived as being personally relevant and important to the individual (in this case, $77 \%$ of all participants reported to the competition was "important" or "very important" to them).

Because failure is equally an inherent aspect of competition (in fact, even more given the typical low success rates in competitions), it is also important to recognize the negative aspects of participating, and failing, in a competition. One encouraging finding is that a healthy majority of participants reported not finding failure in the least bit demotivating (answer value: 1.0 in 13 people out of 29 or $45 \%$ ), and ten more said it was either "somewhat demotivating" (answer value: 2.0 from four people or $14 \%$ ) or "neither discouraging nor encouraging" (answer value: 3.0 from six people or $21 \%)$. Still, six people $(21 \%)$ reported feeling "discouraged" (answer value 4.0), which, while not high, is not negligible and needs to be addressed in a well-designed competition design (Table 2).

Table 2 The experience of failure

\begin{tabular}{l|l|l|l|l|l}
\hline & $\begin{array}{l}\text { (1) Not } \\
\text { at all }\end{array}$ & $\begin{array}{l}\text { (2) A } \\
\text { little }\end{array}$ & $\begin{array}{l}\text { (3) Neither one nor } \\
\text { the other }\end{array}$ & $\begin{array}{l}\text { (4) } \\
\text { Disappointing/ } \\
\text { demotivating }\end{array}$ & $\begin{array}{l}\text { (5) Very } \\
\text { disappointing/ } \\
\text { demotivating }\end{array}$ \\
\hline $\begin{array}{l}\text { How disappointing } \\
\text { was failure? }\end{array}$ & 1 & 7 & 10 & 8 & 3 \\
\hline $\begin{array}{l}\text { How demotivating } \\
\text { was failure? }\end{array}$ & 13 & 4 & 6 & 6 & 0 \\
\hline
\end{tabular}




\section{Conclusions}

The picture emerging from the study's findings suggests that competitions are emotionally intense experiences, and they may influence the participants' wellbeing and future professional choices. The PERMA model provides a useful framework for examining those effects and recommending improvements to competition format.

The most important aspects to be considered in an effective competition include ensuring a scrupulously fair assessment procedure, whose rules should be explained to the participants. Highly selective competitions (with success rates lower than $20 \%$ ) should be avoided unless a form of recognition (vote of distinction, organizer's list, more prizes) can be devised to acknowledge excellent performance in participants who were ultimately unsuccessful.

The competition itself should be devised as a positive experience. Participants should be discouraged from viewing the competition as a test of skill. A feedback session, no matter how generic or rudimentary, should be provided, and the participants should be made aware of the element of chance involved in any competition to explain that success or failure in a competition is often a matter of luck and minor details. Instead, participants should be invited to treat the competition as a new experience and an opportunity to make new contacts, turning a test into a celebration of their skills and knowledge.

\section{Appendix: The Questionnaire}

The original questionnaire was sent in Polish to ensure a higher response rate. The following is a translation of the questions. The answers ranged from 1 (not at all) to 5 (very much).

1. How much did the competition matter to you (in any way: emotional, professional, educational, etc.)?

2. Did you share the news of your success/failure with other people (in person, on social media, etc.)?

3. How positive/negative was the experience of success/failure in your case?

4. To what extent would you agree with the following statement "When working on my entry, for long stretches of time I became so intensely involved that I lost track of time and everything around me"?

5. To what extent would you agree with the following statement "Competitions give an accurate reflection of the participants' skills"?

6. To what extent would you agree with the following statement "Competitions are a bit of a lottery: of the best people don't always win, and the winners are not always the best people"?

7. To what extent was your success/failure encouraging/discouraging in your plans to become a professional translator? 
8. In terms of your motivation to take part, how important was it for you to gain a new experience?

9. In terms of your motivation to take part, how important was it for you to establish new contacts?

10. In terms of your motivation to take part, how important was it for you to see what you're capable of?

11. In terms of your motivation to take part, how important was it for you to do something meaningful in life?

12. In terms of your motivation to take part, how important was it for you to advance your professional career (boost your resume)?

\section{References}

Bain, K. (2004). What the best college teachers do. Cambridge, Mass.: Harvard University Press.

Burger, E. B., \& Starbird, M. (2012). The 5 elements of effective thinking. Princeton, NJ: Princeton University Press.

Cook, C., Heath, F., \& Thompson, R. L. (2000). A meta-analysis of response rates in web- or internet-based surveys. Educational and Psychological Measurement, 60(6), 821-836.

Csikszentmihályi, M. (1988). Optimal experience: Psychological studies of flow. Cambridge: Cambridge University Press.

Csikszentmihályi, M. (1990). Flow: The psychology of optimal experience. New York: Harper \& Row.

Csikszentmihályi, M. (2003). Good business: Leadership, flow and the making of meaning. London: Coronet.

Danziger, S., Levav, J., \& Avnaim-Pesso, L. (2011). Extraneous factors in judicial decisions. Proceedings of the National Academy of Sciences, 108(17), 6889-6892. http://doi.org/10.1073/ pnas. 1018033108

Duckworth, A. L., \& Quinn, P. D. (2009). Development and validation of the short grit scale (Grit-S). Journal of Personality Assessment, 91(2), 166-174. http://doi.org/10.1080/ 00223890802634290

Hill, M., \& Wise, J. (2012). The works of Graham Greene: A reader's bibliography and guide. London: Bloomsbury Publishing.

Kahneman, D. (2011). Thinking, fast and slow. New York: Straus and Giroux.

Kohn, A. (1987). The case against competition. Working Mother. Retrieved from http://www. alfiekohn.org/article/case-competition/

Mercer, S., \& MacIntyre, P. D. (2014). Introducing positive psychology to SLA. Studies in Second Language Learning and Teaching, 2, 153-172. http://doi.org/10.14746/ssllt.2014.4.2.2

Nord, C. (2005). Training functional translators. In M. Tennent (Ed.), Training for the new millennium: Pedagogies for translation and interpreting (pp. 209-224). Amsterdam/Philadelphia: John Benjamins Publishing Company.

Nulty, D. D. (2008). The adequacy of response rates to online and paper surveys: What can be done? Assessment and Evaluation in Higher Education, 33(3), 301-314. http://doi.org/10. 1080/02602930701293231

Pandel, H. (2015). Healthy competition is good for children. IPA Review, 31-33. Retrieved from https://ipa.org.au/publications/2348/healthy-competition-is-good-for-children

Paterculus, C. V. (1721). The roman history of C. Velleius Paterculus. In two books. Translated from the Oxford edition, and collated with all the former ones of Note. By Thomas Newcomb, M. A. Chaplain to His Grace the Duke of Richmond. To which is prefixed, a character of the 
author, and his writings, extracted from Mons. Bayle, and others. (T. Newcomb, Trans.). London: printed for John Pemberton, at the Golden-Buck against St. Dunstan's Church in Fleet-Street.

Petrilli, M. J. (2012, March 26). Alfie Kohn's message: Half-crazy, half-true. Retrieved July 30, 2015, from http://edexcellence.net/commentary/education-gadfly-daily/flypaper/2012/halfcrazy-half-true.html

Rimm, S. (1995). Why gifted kids have poor grades: And what you can do about it. New York: Crown Publishers.

Seligman, M. E. P. (2011). Flourish: A visionary new understanding of happiness and well-being. New York, London, Toronto, Sydney: Free Press.

Seneca, L. A. (1925). Moral letters to Lucilius (Epistulae morales ad Lucilium) (R. M. Gummere, Trans.) (Vol. 3). London: W. Heinemann.

Shields, D. L., \& Funk, C. (2011). Teach to compete. Strategies a Journal for Physical and Sport Educators, 24(5), 8-11.

Szymczak, P. (2013). Translating Wikipedia articles: A preliminary report on authentic translation projects in formal translator training. Acta Philologica, (44), 61-70. Retrieved from http://acta. neofilologia.uw.edu.pl/archiwum/acta44.pdf

Willingham, D. (2009, February 2). Alfie Kohn is bad for you and dangerous for your children. Retrieved July 30, 2015, from http://blogs.britannica.com/2009/02/alfie-kohn-is-bad-for-youand-dangerous-for-your-children/

Wisenberg Brin, D. (2015). Why you should hire for potential, not experience. Retrieved February 5, 2016, from http://www.fastcompany.com/3035990/hit-the-ground-running/why-you-shouldhire-for-potential-not-experience 